\title{
Determining the minimally important difference in quadriceps strength in individuals with COPD using a fixed dynamometer
}

This article was published in the following Dove Press journal: International Journal of COPD

\author{
Trija Vaidya ${ }^{1,2}$ \\ Marc Beaumont ${ }^{3,4}$ \\ Claire de Bisschop' \\ Lucie Bazerque ${ }^{5}$ \\ Camille Le Blanc ${ }^{6}$ \\ Anne Vincent ${ }^{7}$ \\ Hakima Ouksel ${ }^{8}$ \\ Arnaud Chambellan ${ }^{2,9}$
}

'Laboratory MOVE (EA63|4),

Faculty of Sport Sciences, University

of Poitiers, Poitiers, France;

${ }^{2}$ Laboratory "Movement, Interactions,

Performance" (EA4334), Faculty

of Sport Sciences, University of

Nantes, Nantes, France; ${ }^{3}$ Pulmonary

Rehabilitation unit, Morlaix Hospital

Centre, Morlaix, France; ${ }^{4}$ EA3878

(G.E.T.B.O), CHU Brest, Brest, France;

Institute of Physical Education and

Sports Sciences (IFEPSA), Université

Catholique de l'Ouest (UCO),

Angers, France; ${ }^{6}$ Physical Medicine and

Rehabilitation Department, University

Hospital of Nantes, Nantes, France;

${ }^{7}$ Respiratory Rehabilitation Service, la

Tourmaline, UGECAM, Nantes, France;

${ }^{8}$ Dept of Pulmonary Medicine, Angers

University Hospital, Angers, France;

9''institut du Thorax, University

Hospital of Nantes, Nantes, France

Correspondence: Arnaud Chambellan Explorations Fonctionnelles, l'Institut du Thorax, CHU de Nantes, Boulevard Jacques Monod, Nantes 44093, France

Tel +33 240 I65 5 II

Fax +33 $240 \quad 16539$

Email arnaud.chambellan@chu-nantes.fr
Background: Measurement of quadriceps muscular force is recommended in individuals with COPD, notably during a pulmonary rehabilitation program (PRP). However, the tools used to measure quadriceps maximal voluntary contraction (QMVC) and the clinical relevance of the results, as well as their interpretation for a given patient, remain a matter of debate. The objective of this study was to estimate the minimally important difference (MID) of QMVC using a fixed dynamometer in individuals with COPD undergoing a PRP.

Methods: Individuals with COPD undergoing a PRP were included in this study. QMVC was measured using a dynamometer (MicroFET2) fixed on a rigid support according to a standardized methodology. Exercise capacity was measured by 6-minute walk distance (6MWD) and evaluation of quality of life with St George's respiratory questionnaire (SGRQ) and Hospital Anxiety and Depression Scale (HADS) total scores. All measures were obtained at baseline and the end of the PRP. The MID was calculated using distribution-based methods.

Results: A total of 157 individuals with COPD (age 62.9 \pm 9.0 years, forced expiratory volume in 1 second $47.3 \% \pm 18.6 \%$ predicted) were included in this study. At the end of the PRP, the patients had improved their quadriceps force significantly by $8.9 \pm 15.6 \mathrm{Nm}(P<0.001)$, as well as 6MWD by $42 \pm 50 \mathrm{~m}(P<0.001)$, SGRQ total score by $-9 \pm 17(P<0.001)$ and HADS total score by $-3 \pm 6(P<0.001)$. MID estimation using distribution-based analysis was $7.5 \mathrm{Nm}$ by empirical rule effect size and $7.8 \mathrm{Nm}$ by Cohen's effect size.

Conclusion: Measurement of QMVC using a fixed dynamometer is a simple and valuable tool capable of assessing improvement in quadriceps muscle force after a PRP. We suggest an MID of 7.5 Nm to identify beneficial changes after a PRP intervention.

Keywords: COPD, QMVC, muscular dysfunction, dynamometer, pulmonary rehabilitation

\section{Introduction}

Along with limitations in respiratory capacity, peripheral or limb-muscle dysfunction is a widely recognized consequence of $\mathrm{COPD},{ }^{1}$ causing particularly quadriceps-muscle weakness. ${ }^{2,3}$ A reduction of $30 \%$ in quadriceps muscular force among the patients with COPD has been observed when compared to healthy elderly volunteers. ${ }^{4}$ This is mainly attributed to reduction in lean mass and a decrease in the cross-sectional area of the muscle, ${ }^{5,6}$ as well as decreased muscular endurance and increased susceptibility to fatigue, ${ }^{7}$ further worsening a sedentary lifestyle. It has also been observed that despite the respiratory problems, individuals with COPD stop exercise, not due to the breathlessness, but rather due to the perception of leg fatigue. ${ }^{8}$ The prevalence of reduced quadriceps strength has also been reported in other chronic diseases such as diabetes ${ }^{9}$ and chronic heart failure (CHF), ${ }^{10}$ serving as a predictor of mortality in 
the latter ${ }^{11}$ and in COPD. ${ }^{12}$ Moreover, quadriceps muscular force represents a valuable target to measure, as it allows identification of responders to a pulmonary rehabilitation program (PRP). ${ }^{13}$ Among the different techniques ${ }^{14}$ to measure quadriceps strength, the use of a handheld dynamometer ${ }^{15}$ for the evaluation of quadriceps maximal voluntary contraction (QMVC), where resistance is applied by the operator either directly on the device ${ }^{16}$ or by the use of straps, ${ }^{17}$ is known to be a simple and reproducible method. ${ }^{18}$ The technique, though well known as a handheld method, also accepts the use of a stabilization belt to fix the dynamometer on a rigid support that limits operator-induced bias. ${ }^{19}$ The simplicity of this method makes it possible to conduct this measurement in any clinical setting with minimal equipment. Despite its usage over rather a long time, we lack information on what an improvement in this measure really signifies for patients.

There have been previous studies on the evolution of quadriceps strength after a rehabilitation program in chronic diseases, such as diabetes ${ }^{20}$ and CHF. ${ }^{21}$ In COPD, a significant increase in quadriceps strength by $8 \%$ following aerobic training and 20\% following combined aerobic and strength training have been identified. ${ }^{22}$ Although differing in methodology of measurement, the study of change in quadriceps strength after an intervention of rehabilitation is of great value. However, its minimally important difference (MID) remains unknown. The MID is a useful expression defined as "the minimal amount of change required between two points in time to be confident that a patient has truly changed". ${ }^{23}$ A reduction of $4 \%$ in isometric force has been suggested as the minimal change to bring about a relevant difference in osteoarthritis of the knee. ${ }^{24}$ Similarly, a preliminary result by Quessada et al suggested an MID of $33 \mathrm{Nm}$ for QMVC in individuals with COPD undergoing exercise training. ${ }^{25}$ As preliminary data from a small sample, these results and the insight on the technique of measurement remain to be confirmed in a larger population. From this perspective, we aimed to determine the MID for QMVC using a simple fixed dynamometer in individuals with COPD undergoing a PRP.

\section{Methods}

\section{Subjects}

Patients were included in the study if they fulfilled the inclusion criteria of a diagnosis of COPD according to the Global initiative for Chronic Obstructive Lung Disease (GOLD) recommendations, ${ }^{26}$ having completed a PRP including exercise training and education component as recommended, ${ }^{27}$ and written consent signed by the patient prior to the beginning of the program. Patients from Nantes were included in the cohort RehaEffort from the Institut de Recherche en Santé Respiratoire des Pays de la Loire and patients from North Brittany were from the Centre Hospitalier des Pays de Morlaix. Exclusion criteria were the presence of a lower-limb lesion hampering the measurement of quadriceps strength and the presence of joint limitations. The patients were recruited in three different centers in two cities of France: the University Hopsital of Nantes and the Tourmaline Medical Centre in Nantes and the Centre Hospitalier des Pays de Morlaix in Morlaix. In Nantes, the study was conducted by the RehaEffort cohort group from the Institut de Recherche en Santé Respiratoire des Pays de la Loire, for which approval was obtained from the ethical board (Comité de Protection des Personnes [CPP] - 2009/17) and the Comité Consultatif sur le Traitement de l'Information en Matière de Recherche dans le Domaine de la Santé [CCTIRS] (07.207 bus). Patients from the Centre Hospitalier des Pays de Morlaix signed a written informed consent in accordance with the Declaration of Helsinki and the current guidelines for Good Clinical Practice after approval by the institutional medical ethics committees (CPP Ouest 6 - CPP803, 2013-A01180-45).

\section{Study design}

All patients included went through a complete outpatient or inpatient evaluation in the institutions to assess individual deficiency, incapacity, and social disadvantage, as recommended. ${ }^{27}$ Pulmonary function tests, including spirometry, plethysmography, and diffusion capacity, were conducted according to European Respiratory Society and American Thoracic Society task-force recommendations. ${ }^{28,29}$ All patients performed a cardiopulmonary exercise test using a progressive $10 \mathrm{~W}$ incremental test on an electromagnetically braked cycle ergometer up to exhaustion, as recommended. ${ }^{30}$ A 6-minute walk test (6MWT) was also performed, and dyspnea was assessed using the Modified Medical Research Council (mMRC) scale. Evaluation of health-related quality of life (HRQoL) was done with St George's respiratory questionnaire (SGRQ) total score, and anxiety and depression with Hospital Anxiety and Depression Scale (HADS) total score. Along with these, nutritional assessment, evaluation of comorbidities, and treatments were done. Evaluation of exercise capacity, dyspnea, HRQoL, anxiety, and depression were conducted at baseline and the end of the PRP.

\section{Pulmonary rehabilitation}

All the centers included in the study followed the standardized PRP as per the recommendations, ${ }^{31}$ with variations in 
their modalities, including home-based, center-based, and outpatient-based programs in Nantes and center-based or outpatient-based programs in Morlaix. A further description of the PRP content is provided in the Supplementary material.

\section{Quadriceps maximal voluntary contraction}

For measurement of QMVC, an adaptation of the wellestablished method using a MicroFET2 dynamometer (Hoggan Scientific, Salt Lake City, UT, USA) was used. ${ }^{19}$ To ensure proper measurement, the patient sat comfortably on the examination table with a high-density triangular corner cushion under the knees, in order to guarantee alignment of the femur and provide countersupport at the knees. Hip and knee were positioned at $90^{\circ}$ flexion. ${ }^{32}$ The device was fixed on the leg of the examination table with a strap to prevent any operator bias. A second strap was then used to fix the leg to the device. The point of application of force was $5 \mathrm{~cm}$ above the medial malleolus of the tibia. The moment of force was calculated with measurement of the lever arm between the knee-joint center and the point of application of force. As the measure of QMVC is known to have a learning effect, ${ }^{33}$ a minimum of three measures was obtained for each leg. The best value obtained was then taken as the absolute value. These measurements are expressed in Newton meters.

\section{Statistical analysis}

All results are presented as means \pm SD or percentages. Comparison of baseline characteristics among the three centers was done by one-way analysis of variance (ANOVA). Variables that changed significantly from baseline to the end of the PRP were identified by paired $t$-tests in cases of normality of distribution of values or the Wilcoxon test if not normally distributed. All statistical analyses were performed using SigmaPlot 11.0 and SPSS Statistics 19 (IBM, Armonk, NY, USA). QMVC and the 6-minute walk distance (6MWD) measurements were standardized using $z$-scores. A $z$-score gives a quantified distance from the normative data in the SD in respect to the average reference performance of the population selected, which means that $z$-scores help us to compare the observed value of measurement to a normal population. A $z$-score of -1.64 signifies that the value measured lies in the fifth percentile.

The equation used was $z$-score $=($ Observed value Predicted value)/SD. The predicted value for QMVC was taken from Hogrel et $\mathrm{al}^{34}$ and for 6MWD from Troosters et al. ${ }^{35}$ Statistical significance of comparisons was set at $P<0.05$.

\section{Calculation of MID}

For MID estimation, distribution- and anchor-based methods were used. ${ }^{36}$ The distribution-based method uses the distribution of observed values in a given sample to estimate MID. Distribution-based methods used in this study were empirical rule effect size $\left(0.08 \times 6 \times \mathrm{SD}_{\text {end-baseline }}\right)$ and Cohen's effect size $\left(0.5 \times \mathrm{SD}_{\text {end-baseline }}\right)$. The anchor-based method uses an external indicator with its known MID in the target population. In this study, the possible anchors were 6MWD, with its MID of $30 \mathrm{~m},{ }^{37}$ and SGRQ total score, with its MID of -4 points. ${ }^{38}$ For a potential anchor to be selected using this approach as per recommendations, the change from baseline must correlate with the change in QMVC with a correlation coefficient $\geq 0.3$ and $P<0.05$. $^{36}$

\section{Results}

A total of 157 eligible individuals with COPD were included in the study from February 2014 to January 2016. The characteristics of the subjects included are given in Table 1. Comparison of baseline characteristics among the three centers is given in Table S1.

Table I Baseline characteristics of the patients

\begin{tabular}{ll}
\hline $\mathrm{n}$ & 157 \\
Male/female & $93 / 64$ \\
Age, years & $63 \pm 9$ \\
BMI, kg/m² & $26 \pm 6$ \\
Dyspnea, mMRC & $2 \pm 1$ \\
Lung function & \\
FEV, \% predicted & $47 \pm 19$ \\
FVC, \% predicted & $79 \pm 23$ \\
FEV $/$ /FVC, \% & $45 \pm 16$ \\
GOLD I, n (\%) & $8(5)$ \\
GOLD 2, n (\%) & $58(37)$ \\
GOLD 3, n (\%) & $64(4 I)$ \\
GOLD 4, n (\%) & $27(17)$ \\
QMVC, Nm & $96 \pm 37$ \\
6MWD, m & $392 \pm 107$ \\
6MWD, \% predicted & $68 \pm 19$ \\
SGRQ total score & $53 \pm 16$ \\
HADS & \\
Anxiety & $8 \pm 4$ \\
Depression & $7 \pm 4$ \\
Total & $15 \pm 7$ \\
BODE index & $4 \pm 2$ \\
\hline
\end{tabular}

Notes: Data presented as mean \pm SD unless otherwise indicated. Predicted values for 6MWD taken from Troosters et al. ${ }^{35}$

Abbreviations: BMI, body-mass index; mMRC, modified Medical Research Council (scale); FEV , forced expiratory volume in I second; FVC, forced vital capacity; GOLD, Global Initiative for Chronic Obstructive Lung Disease; QMVC, quadriceps maximal voluntary contraction; 6MWD, 6-minute walk distance; SGRQ, St George's respiratory questionnaire; HADS, Hospital Anxiety and Depression Scale; BODE, body mass, airflow obstruction, dyspnea, and exercise. 
Table 2 Changes in parameters measured at baseline and end of PRP

\begin{tabular}{lllll}
\hline & Baseline & End & $\begin{array}{l}\text { Change } \\
\text { (absolute) }\end{array}$ & $\begin{array}{l}\text { Change } \\
(\%)\end{array}$ \\
\hline QMVC, Nm & $96 \pm 37$ & $105 \pm 40$ & $9 \pm 16$ & $11 \pm 19^{\mathrm{a}}$ \\
6MWD, m & $392 \pm 107$ & $438 \pm 102$ & $42 \pm 50$ & $13 \pm 17^{\mathrm{a}}$ \\
SGRQ total & $53 \pm 16$ & $44 \pm 16$ & $-9 \pm 17$ & $-13 \pm 25^{\mathrm{a}}$ \\
HADS & & & & \\
$\quad$ Anxiety & $8 \pm 4$ & $7 \pm 4$ & $-2 \pm 3$ & $-15 \pm 47^{\mathrm{a}}$ \\
$\quad \begin{array}{l}\text { Depression } \\
\text { Total }\end{array}$ & $7 \pm 4$ & $5 \pm 4$ & $-1 \pm 3$ & $-14 \pm 52^{\mathrm{a}}$ \\
\hline
\end{tabular}

Notes: ${ }^{a}<<0.001$. Data presented as mean \pm SD.

Abbreviations: PRP, pulmonary rehabilitation program; QMVC, quadriceps maximal voluntary contraction; 6MWD, 6-minute walk distance; SGRQ, St George's respiratory questionnaire; HADS, Hospital Anxiety and Depression Scale.

\section{Responsiveness to PRP}

Changes in parameters between baseline and the end of the PRP are given in Table 2. Subjects improved quadriceps force, 6MWD, and HRQoL significantly. Comparison of the intervention effect on the parameters evaluated at baseline and the end of the PRP at the three centers is given in Table S2.

\section{Evolution of QMVC and 6MWD z-scores}

There was significant evolution in QMVC and 6MWD $z$-scores between baseline and the end of the PRP $(-0.8 \pm 0.7$ to $-0.4 \pm 0.7[P<0.001]$ for $\mathrm{QMVC}$ and $-1.7 \pm 1.1$ to $-1.4 \pm 1.0$ $[P<0.001]$ for 6MWD; Figure 1). At the end of the PRP, subjects had improved their 6MWD, and average $z$-score $(-1.4 \pm 1.0)$ was found to be within the 90th percentile.

\section{Determination of MID}

Using distribution-based methods, the MID for QMVC was 7.5 Nm for empirical rule effect size and 7.8 Nm for Cohen's

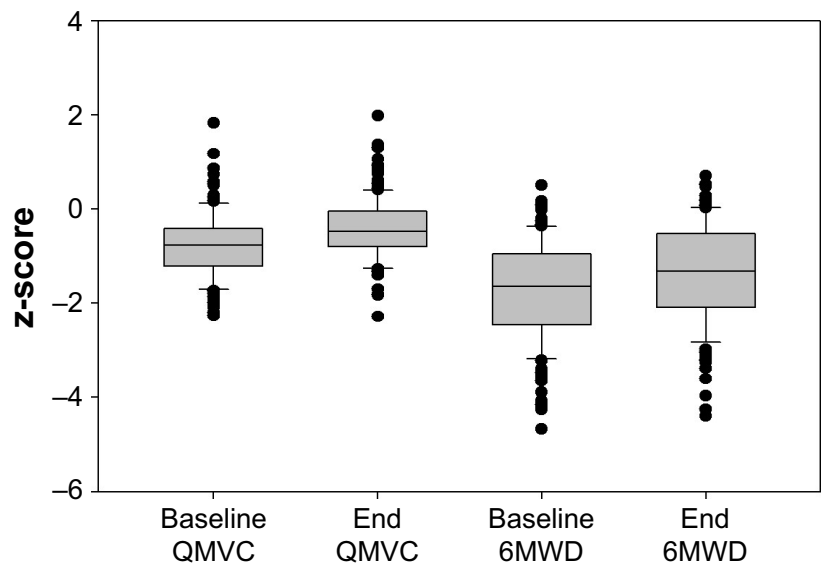

Figure I Box plot of changes in z-scores of QMVC and 6MWD from baseline to the end of the PRP.

Abbreviations: QMVC, quadriceps maximal voluntary contraction; 6MWD, 6-minute walk distance; PRP, pulmonary rehabilitation program. effect size. The change in QMVC failed to correlate with either the change in 6MWD ( $r=-0.032, P=0.686)$ or with change in SGRQ total score $(r=0.006, P=0.937)$. As such, no anchor could be identified in this analysis. The distribution of the subjects with the changes in 6MWD and SGRQ total scores in terms of the MID of 7.5 Nm in QMVC and MIDs of $30 \mathrm{~m}$ for $6 \mathrm{MWD}$ and -4 points for the SGRQ is given in Figure 2.

\section{Discussion}

In this study, we report the MID for QMVC in individuals with COPD undergoing a PRP. Our findings suggest 7.5 Nm to be the minimal change in QMVC attributed to the intervention of a PRP. Even though the measure of QMVC has been in place for a long time, a question remains as to what this measure actually means with regard to meaningful improvement for a patient and how the person perceives this muscular force in daily life. The diminution in muscular force with disease progression is common among individuals with COPD. Therefore, the assessment of quadriceps force seems relevant, especially if the interest is to evaluate the effect of such an intervention as a rehabilitation program. The measure of quadriceps force appears of interest along with the evaluation of daily activity in chronic diseases, as movement like getting up from a chair and moving around involves the use of quadriceps muscles. We previously found a significant correlation between changes in QMVC after a PRP and 1-minute sit-to-stand test, ${ }^{39}$ which involves repeated contractions of quadriceps muscles for a longer time, requiring force and endurance capacities. Apart from activities of daily living, good quadriceps muscular force can also reduce the risk of falls in these patients. Studies have shown strong correlations between lower-limb-muscle weakness and increased fall incidence among elderly people. ${ }^{40}$ In COPD, an increased risk of falls is associated with quadriceps weakness resulting from exacerbation and related hospitalization. ${ }^{41}$ This further adds to the interest of QMVC measurement in COPD. The evaluation of QMVC by dynamometer in our study was performed by fixing the device with a strap to the leg of the examination table to avoid operator-influenced bias. It is important to note that the handheld method using this device is known to be influenced by the strength of the operator when applied manually. ${ }^{42}$

Our study estimated the MID of QMVC in individuals with COPD. To our knowledge, this is the first study to address MID calculation for QMVC in COPD. There have been a few studies that focused on the evolution of quadriceps strength after an intervention. Nishitani et al provided evidence of an improvement in muscle strength in individuals 

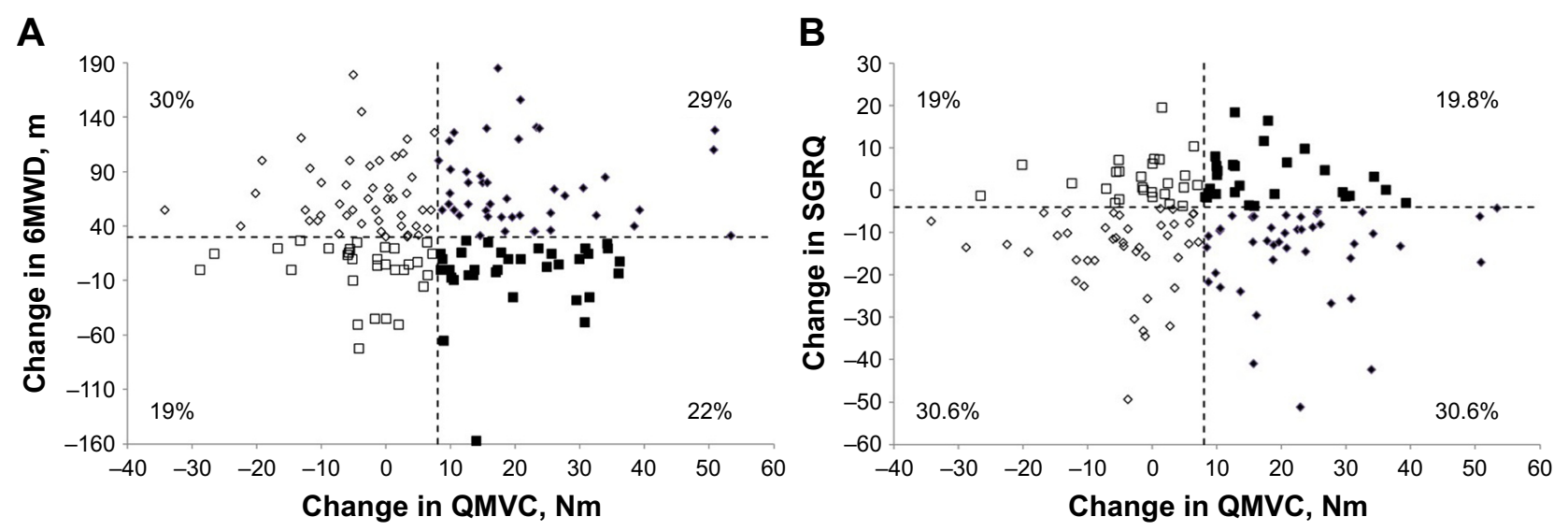

Figure 2 Distribution of subjects.

Notes: (A) Subjects with changes in QMVC and 6MWD in terms of respective MIDs of $7.5 \mathrm{Nm}$ and $30 \mathrm{~m}$; (B) subjects with changes in QMVC and SGRQ in terms of respective MIDs of $7.5 \mathrm{Nm}$ and -4 points.

Abbreviations: QMVC, quadriceps maximal voluntary contraction; 6MWD, 6-minute walk distance; MIDs, minimally important differences; SGRQ, St George's respiratory questionnaire.

with diabetes mellitus after cardiac rehabilitation of 6 months following coronary artery-bypass grafting. ${ }^{20}$ Similarly, in individuals with CHF and COPD, evolution of quadriceps strength was compared between an exercise rehabilitation of 7 weeks and usual care. There was no difference between groups, perhaps because the exercise program included mainly endurance training, as justified by the authors. ${ }^{21}$ Bernard et al showed a significant increase of $20 \%$ in quadriceps strength following aerobic and strength training in COPD. ${ }^{22}$ Despite studies including quadriceps-strength measurement in COPD and pulmonary rehabilitation, a possible MID has been less explored. All these studies also differed in the method of evaluation of quadriceps strength. We found a preliminary report on MID for QMVC in COPD by Quessada et al, where the technique of measurement was not provided in detail and thus cannot be presumed to be totally comparable. ${ }^{25}$

The estimation of MID in our study was done using distribution-based methods only, as the change in QMVC and the possible anchors failed to correlate. In this study, we chose the 6MWD and SGRQ as possible anchors, due to their known MID and relevance in the COPD population undergoing a PRP. QMVC expresses maximal strength of the muscle, whereas the 6MWD is an aerobic functional test. The reorganization of muscle-fiber type in COPD, as per Gosker et al, ${ }^{43}$ could also result in differences in performance during these two evaluations, suggesting that they evaluate different dimensions of functional capacity. Quadriceps force has been identified as a determinant of $6 \mathrm{MWD},{ }^{44}$ but it should be noted that our interest lies in the comparison between the change measured in each of these evaluations. The low correlation between changes in QMVC and 6MWD suggests that evolution of either of the evaluations is not correlated with the other, further confirming a difference in the dimensions that they measure. Similarly, variability in the correlation between a physical performance and $\mathrm{QoL}$ has previously been shown, ${ }^{45}$ which could agree with our nonsignificant correlation between QMVC and SGRQ. It is however usual for MID calculation to be based on the distribution of observed scores. Similar methods have been used to calculate MIDs for exercise tests in COPD, such as the 6MWT and 6-minute stepper test. ${ }^{46,47}$ These statistical methods, based on distribution of values, resulted in variation in MID from $7.5 \mathrm{Nm}$ to $7.8 \mathrm{Nm}$. Taking these MID ranges into account, $>50 \%$ of subjects were able to improve their quadriceps force after the PRP. It should also be noted that our study focused on the minimally significant change for an improvement in QMVC and not deterioration. The interpretation of improvement and deterioration may not be likely to be similar when presented in a patient-reported outcome, which is often used in the anchor-based MID estimation. This variation could result in different MIDs for improvement and deterioration of a measure. ${ }^{48}$ The MID estimation, however, in our study gives a cutoff value for improvement of quadriceps strength.

It appears important to distinguish the different MID calculations and to analyze their advantages and limits. Copay et $a l^{49}$ listed three limitations of MID determinations: each method estimates a different MID value, MID calculation does not consider the cost of the treatment (further studies are necessary to investigate this point), and the change in patientreported outcome depends on the baseline status of the patient. Along with these, the study had some limitations. The first is the absence of a control group. The findings of this study could have been strengthened with a control group. The second limitation is the difference in duration of the PRP among the 
centers. A center effect is not excluded, but probably limited here by the fact that the subjects recruited in all three centers had similar baseline characteristics, which made it possible to combine the observed values. This approach justifies the interest of a multicenter study. Although there were some differences in duration, the program content was as per the recommendations in all the centers, thus leading to similar changes observed after the PRP whatever the origin of the patients. Moreover, our results showed that all PRPs produced significant improvements, which is comparable to previous studies. ${ }^{50,51}$ The third limitation is the absence of follow-up data after the PRP. Further studies are required to investigate the long-term maintenance of muscle-strength improvement.

\section{Conclusion}

Assessment of QMVC using a fixed dynamometer is a simple evaluation of quadriceps muscular force and capable of assessing improvement after a PRP among COPD patients. A gain of at least $7.5 \mathrm{Nm}$ represents a meaningful improvement in quadriceps force after a PRP.

\section{Acknowledgments}

The authors would like to acknowledge colleagues from the following teams who were involved in taking care of the patients in pulmonary rehabilitation and assisting with inclusion: Véronique Jean from the Pulmonary Rehabilitation Department in Saint-Jacques Hospital, University Hospital of Nantes and François Dessables from the Tourmaline Medical Center in Nantes.

\section{Disclosure}

The authors report no conflicts of interest in this work.

\section{References}

1. Maltais F, Decramer M, Casaburi R, et al. An official American Thoracic Society/European Respiratory Society statement: update on limb muscle dysfunction in chronic obstructive pulmonary disease. Am J Respir Crit Care Med. 2014;189(9):e15-e62.

2. Seymour JM, Spruit MA, Hopkinson NS, et al. The prevalence of quadriceps weakness in COPD and the relationship with disease severity. Eur Respir J. 2010;36(1):81-88.

3. Kharbanda S, Ramakrishna A, Krishnan S. Prevalence of quadriceps muscle weakness in patients with COPD and its association with disease severity. Int J Chron Obstruct Pulmon Dis. 2015;10:1727-1735.

4. Man WD, Soliman MG, Nikoletou D, et al. Non-volitional assessment of skeletal muscle strength in patients with chronic obstructive pulmonary disease. Thorax. 2003;58(8):665-669.

5. Agusti A, Soriano JB. COPD as a systemic disease. COPD. 2008;5(2): 133-138.

6. Marquis K, Debigaré R, Lacasse Y, et al. Midthigh muscle cross-sectional area is a better predictor of mortality than body mass index in patients with chronic obstructive pulmonary disease. Am J Respir Crit Care Med. 2002;166(6):809-813.
7. Evans RA, Kaplovitch E, Beauchamp MK, et al. Is quadriceps endurance reduced in COPD? A systematic review. Chest. 2015;147(3): 673-684.

8. Killian KJ, Leblanc P, Martin DH, Summers E, Jones NL, Campbell EJ. Exercise capacity and ventilatory, circulatory, and symptom limitation in patients with chronic airflow limitation. Am Rev Respir Dis. 1992;146(4):935-940.

9. Volpato S, Bianchi L, Lauretani F, et al. Role of muscle mass and muscle quality in the association between diabetes and gait speed. Diabetes Care. 2012;35(8):1672-1679.

10. Harrington D, Anker SD, Chua TP, et al. Skeletal muscle function and its relation to exercise tolerance in chronic heart failure. $J$ Am Coll Cardiol. 1997;30(7):1758-1764.

11. Kamiya K, Masuda T, Tanaka S, et al. Quadriceps strength as a predictor of mortality in coronary artery disease. Am J Med. 2015;128(11): $1212-1219$.

12. Swallow EB, Reyes D, Hopkinson NS, et al. Quadriceps strength predicts mortality in patients with moderate to severe chronic obstructive pulmonary disease. Thorax. 2007;62(2):115-120.

13. Walsh JR, Morris NR, Mckeough ZJ, Yerkovich ST, Paratz JD. A simple clinical measure of quadriceps muscle strength identifies responders to pulmonary rehabilitation. Pulm Med. 2014;2014:782702.

14. Moss CL, Wright PT. Comparison of three methods of assessing muscle strength and imbalance ratios of the knee. J Athl Train. 1993; 28(1):55-58.

15. Saey D, Troosters T. Measuring skeletal muscle strength and endurance, from bench to bedside. Clin Invest Med. 2008;31(5):307-311.

16. Bohannon RW. Hand-held dynamometry: adoption 1900-2005. Percept Mot Skills. 2006;103(1):3-4.

17. Whiteley R, Jacobsen P, Prior S, Skazalski C, Otten R, Johnson A. Correlation of isokinetic and novel hand-held dynamometry measures of knee flexion and extension strength testing. J Sci Med Sport. 2012;15(5):444-450.

18. O'Shea SD, Taylor NF, Paratz JD. Measuring muscle strength for people with chronic obstructive pulmonary disease: retest reliability of hand-held dynamometry. Arch Phys Med Rehabil. 2007;88(1):32-36.

19. Bohannon RW, Kindig J, Sabo G, Duni AE, Cram P. Isometric knee extension force measured using a handheld dynamometer with and without belt-stabilization. Physiother Theory Pract. 2012;28(7):562-568.

20. Nishitani M, Shimada K, Masaki M, et al. Effect of cardiac rehabilitation on muscle mass, muscle strength, and exercise tolerance in diabetic patients after coronary artery bypass grafting. $J$ Cardiol. 2013;61(3):216-221.

21. Evans RA, Singh SJ, Collier R, Loke I, Steiner MC, Morgan MD. Generic, symptom based, exercise rehabilitation: integrating patients with COPD and heart failure. Respir Med. 2010;104(10):1473-1481.

22. Bernard $\mathrm{S}$, Whittom $\mathrm{F}$, Leblanc $\mathrm{P}$, et al. Aerobic and strength training in patients with chronic obstructive pulmonary disease. Am J Respir Crit Care Med. 1999;159(3):896-901.

23. Stratford PW, Binkley JM, Riddle DL, Guyatt GH. Sensitivity to change of the Roland-Morris Back Pain Questionnaire: part 1. Phys Ther. 1998;78(11):1186-1196.

24. Ruhdorfer A, Wirth W, Eckstein F. Relationship between isometric thigh muscle strength and minimum clinically important differences in knee function in osteoarthritis: data from the osteoarthritis initiative. Arthritis Care Res (Hoboken). 2015;67(4):509-518.

25. Quessada A, Nellessen AG, Bisca GW, et al. Minimal important difference of quadriceps femoris muscle strength after high-intensity exercise training in patients with COPD: preliminary results. Eur Respir J. 2014; 44 Suppl 58:P1286.

26. Vestbo J, Hurd SS, Agustí AG, et al. Global strategy for the diagnosis, management, and prevention of chronic obstructive pulmonary disease: GOLD executive summary. Am J Respir Crit Care Med. 2013;187(4): 347-365.

27. Spruit MA, Singh SJ, Garvey C, et al. An official American Thoracic Society/European Respiratory Society statement: key concepts and advances in pulmonary rehabilitation. Am J Respir Crit Care Med. 2013;188(8):e13-e64. 
28. Miller MR, Hankinson J, Brusasco V, et al. Standardisation of spirometry. Eur Respir J. 2005;26(2):319-338.

29. Wanger J, Clausen JL, Coates A, et al. Standardisation of the measurement of lung volumes. Eur Respir J. 2005;26(3):511-522.

30. American Thoracic Society, American College of Chest Physicians. ATS/ACCP statement on cardiopulmonary exercise testing. Am J Respir Crit Care Med. 2003;167(2):211-277.

31. Spruit MA, Pitta F, Mcauley E, Zuwallack RL, Nici L. Pulmonary rehabilitation and physical activity in patients with chronic obstructive pulmonary disease. Am J Respir Crit Care Med. 2015;192(8):924-933.

32. Bachasson D, Villiot-Danger E, Verges $\mathrm{S}$, et al. Maximal isometric voluntary quadriceps strength assessment in COPD. Rev Mal Respir. 2014;31(8):765-770.

33. Reinking MF, Bockrath-Pugliese K, Worrell T, Kegerreis RL, MillerSayers K, Farr J. Assessment of quadriceps muscle performance by hand-held, isometric, and isokinetic dynamometry in patients with knee dysfunction. J Orthop Sports Phys Ther. 1996;24(3):154-159.

34. Hogrel JY, Payan CA, Ollivier G, et al. Development of a French isometric strength normative database for adults using quantitative muscle testing. Arch Phys Med Rehabil. 2007;88(10):1289-1297.

35. Troosters T, Gosselink R, Decramer M. Six minute walking distance in healthy elderly subjects. Eur Respir J. 1999;14(2):270-274.

36. Revicki D, Hays RD, Cella D, Sloan J. Recommended methods for determining responsiveness and minimally important differences for patient-reported outcomes. J Clin Epidemiol. 2008;61(2):102-109.

37. Holland AE, Spruit MA, Troosters T, et al. An official European Respiratory Society/American Thoracic Society technical standard: field walking tests in chronic respiratory disease. Eur Respir J. 2014; 44(6): 1428-1446.

38. Jones PW. Interpreting thresholds for a clinically significant change in health status in asthma and COPD. Eur Respir J. 2002;19(3): 398-404.

39. Vaidya T, de Bisschop C, Beaumont M, et al. Is the 1-minute sit-tostand test a good tool for the evaluation of the impact of pulmonary rehabilitation? Determination of the minimal important difference in COPD. Int J Chron Obstruct Pulmon Dis. 2016;11:2609-2616.
40. Moreland JD, Richardson JA, Goldsmith CH, Clase CM. Muscle weakness and falls in older adults: a systematic review and meta-analysis. J Am Geriatr Soc. 2004;52(7):1121-1129.

41. Roig M, Eng JJ, Road JD, Reid WD. Falls in patients with chronic obstructive pulmonary disease: a call for further research. Respir Med. 2009;103(9):1257-1269.

42. Wikholm JB, Bohannon RW. Hand-held dynamometer measurements: tester strength makes a difference. J Orthop Sports Phys Ther. 1991; 13(4):191-198.

43. Gosker HR, van Mameren H, van Dijk PJ, et al. Skeletal muscle fibretype shifting and metabolic profile in patients with chronic obstructive pulmonary disease. Eur Respir J. 2002;19(4):617-625.

44. Gosselink R, Troosters T, Decramer M. Peripheral muscle weakness contributes to exercise limitation in COPD. Am J Respir Crit Care Med. 1996;153(3):976-980.

45. de Torres JP, Pinto-Plata V, Ingenito E, et al. Power of outcome measurements to detect clinically significant changes in pulmonary rehabilitation of patients with COPD. Chest. 2002;121(4):1092-1098.

46. Puhan MA, Chandra D, Mosenifar Z, et al. The minimal important difference of exercise tests in severe COPD. Eur Respir J. 2011;37(4): 784-790.

47. Pichon R, Couturaud F, Mialon P, et al. Responsiveness and minimally important difference of the 6-minute stepper test in patients with chronic obstructive pulmonary disease. Respiration. 2016;91(5):367-373.

48. Guyatt GH, Osoba D, Wu AW, Wyrwich KW, Norman GR. Methods to explain the clinical significance of health status measures. Mayo Clin Proc. 2002;77(4):371-383.

49. Copay AG, Subach BR, Glassman SD, Polly DW, Schuler TC. Understanding the minimum clinically important difference: a review of concepts and methods. Spine J. 2007;7(5):541-546.

50. Laviolette L, Bourbeau J, Bernard S, et al. Assessing the impact of pulmonary rehabilitation on functional status in COPD. Thorax. 2008; 63(2):115-121.

51. Maddocks M, Kon SS, Canavan JL, et al. Physical frailty and pulmonary rehabilitation in COPD: a prospective cohort study. Thorax. 2016; 71(11):988-995. 


\section{Supplementary materials Pulmonary rehabilitation}

The home-based pulmonary rehabilitation program (PRP) was conducted for 12 weeks, 2 days per week, center-based PRP for 4 weeks, 3 days per week, outpatient-based PRP for 6 weeks, 3 days per week in the centers in Nantes, and center-based or outpatient PRP in Morlaix for 4 weeks, 5 days per week. The standardized PRP in all the centers included aerobic exercise on a cycle ergometer and/or treadmill with a target intensity of $60 \%$ peak work rate regarded as minimum and resistance training of the upperand lower-limb muscles for 30-45 minutes. ${ }^{1,2}$ Along with these, respiratory physiotherapy, a therapeutic educational program, dietary counseling, a smoking-cessation program and sociopsychological support were also included in the PRP.

Table SI Baseline characteristics of the patients from three centers

\begin{tabular}{|c|c|c|c|}
\hline & \multicolumn{2}{|l|}{ Nantes } & \multirow[t]{2}{*}{ Morlaix } \\
\hline & $\begin{array}{l}\text { University Hospital } \\
\text { of Nantes }\end{array}$ & $\begin{array}{l}\text { Tourmaline Medical } \\
\text { Centre }\end{array}$ & \\
\hline $\mathrm{n}$ & 18 & 20 & 119 \\
\hline Male/female & $15 / 3$ & $12 / 8$ & $66 / 53$ \\
\hline Age, years & $63 \pm 7$ & $63 \pm 10$ & $63 \pm 9$ \\
\hline $\mathrm{BMI}, \mathrm{kg} / \mathrm{m}^{2}$ & $25 \pm 6$ & $25 \pm 6$ & $26 \pm 6$ \\
\hline Dyspnea, mMRC & $3 \pm 1$ & $2 \pm 1$ & $2 \pm I^{*}$ \\
\hline \multicolumn{4}{|l|}{ Lung function } \\
\hline $\mathrm{FEV}_{1}, \%$ predicted & $48 \pm 22$ & $48 \pm 17$ & $47 \pm 18$ \\
\hline FVC, \% predicted & $77 \pm 21$ & $75 \pm 22$ & $78 \pm 24$ \\
\hline $\mathrm{FEV}_{1} / \mathrm{FVC}, \%$ & $48 \pm 14$ & $29 \pm 28$ & $48 \pm 12$ \\
\hline GOLD I, n (\%) & I (6) & I (5) & $6(5)$ \\
\hline GOLD 2, n (\%) & $5(28)$ & $8(40)$ & $45(38)$ \\
\hline GOLD 3, n (\%) & $10(56)$ & $9(45)$ & $45(38)$ \\
\hline GOLD 4, n (\%) & $2(I I)$ & $2(10)$ & $27(17)$ \\
\hline QMVC, $\mathrm{Nm}$ & $92 \pm 25$ & $99 \pm 30$ & $96 \pm 40$ \\
\hline 6MWD, m & $304 \pm 101$ & $443 \pm 108^{\ddagger}$ & $397 \pm 101 *$ \\
\hline 6MWD, \% predicted & $53 \pm 17$ & $76 \pm 20^{\ddagger}$ & $69 \pm 18^{*}$ \\
\hline SGRQ total score & $64 \pm 15$ & $52 \pm 18$ & $52 \pm 16 *$ \\
\hline \multicolumn{4}{|l|}{ HADS } \\
\hline Anxiety & $9 \pm 4$ & $8 \pm 4$ & $8 \pm 5$ \\
\hline Depression & $7 \pm 4$ & $6 \pm 4$ & $7 \pm 4$ \\
\hline Total & $16 \pm 7$ & $14 \pm 6$ & $15 \pm 7$ \\
\hline BODE index & $5 \pm 2$ & $4 \pm 2$ & $3 \pm 2$ \\
\hline
\end{tabular}

Notes: $* P<0.05$, significant difference between University Hospital of Nantes’ and Morlaix; $¥ P<0.05$, significant difference between University Hospital of Nantes and Tourmaline Medical Centre. Data presented as mean \pm SD unless otherwise indicated. Predicted values for 6MWD taken from Troosters et al. ${ }^{3}$

Abbreviations: BODE, body mass, airflow obstruction, dyspnea, and exercise; BMI, body-mass index; FEV , forced expiratory volume in I second; FVC, forced vital capacity; GOLD, Global Initiative for Chronic Obstructive Lung Disease; HADS, Hospital Anxiety and Depression Scale; mMRC, modified Medical Research Council (scale); QMVC, quadriceps maximal voluntary contraction; 6MWD, 6-minute walk distance; SGRQ, St George's respiratory questionnaire. 
Table S2 Comparison of the changes in parameters measured at baseline and the end of PRP in the three centers

\begin{tabular}{|c|c|c|c|c|c|c|c|c|c|c|c|c|}
\hline & \multicolumn{8}{|l|}{ Nantes } & \multicolumn{4}{|l|}{ Morlaix } \\
\hline & \multicolumn{4}{|c|}{ University Hospital of Nantes } & \multicolumn{4}{|c|}{ Tourmaline Medical Centre } & \multirow[b]{2}{*}{ Baseline } & \multirow[b]{2}{*}{ End } & \multirow[b]{2}{*}{$\begin{array}{l}\text { Change } \\
\text { (absolute) }\end{array}$} & \multirow[b]{2}{*}{$\begin{array}{l}\text { Change } \\
\text { (\%) }\end{array}$} \\
\hline & Baseline & End & $\begin{array}{l}\text { Change } \\
\text { (absolute) }\end{array}$ & $\begin{array}{l}\text { Change } \\
\text { (\%) }\end{array}$ & Baseline & End & $\begin{array}{l}\text { Change } \\
\text { (absolute) }\end{array}$ & $\begin{array}{l}\text { Change } \\
\text { (\%) }\end{array}$ & & & & \\
\hline QMVC, Nm & $92 \pm 25$ & $108 \pm 26$ & $16 \pm 10$ & $19 \pm 14^{*}$ & $99 \pm 30$ & $116 \pm 40$ & $17 \pm 16$ & $17 \pm 15^{*}$ & $96 \pm 40$ & $103 \pm 42$ & $7 \pm 16$ & $8 \pm 20^{*}, \neq$ \\
\hline 6MWD, m & $304 \pm 101$ & $361 \pm 89$ & $36 \pm 88$ & $13 \pm 27$ & $443 \pm 108$ & $480 \pm 96$ & $36 \pm 48$ & $11 \pm 19 *$ & $397 \pm 101$ & $44 I \pm 100$ & $43 \pm 43$ & $13 \pm 14 *$ \\
\hline SGRQ total & $64 \pm 15$ & $52 \pm 20$ & $-7 \pm 8$ & $-12 \pm 14 *$ & $52 \pm 18$ & $44 \pm 13$ & $-|1 \pm 2|$ & $-16 \pm 45$ & $52 \pm 16$ & $44 \pm 15$ & $-8 \pm 12$ & $-13 \pm 25 *$ \\
\hline \multicolumn{13}{|l|}{ HADS } \\
\hline Anxiety & $9 \pm 4$ & $6 \pm 4$ & $-2 \pm 3$ & $-29 \pm 33 *$ & $8 \pm 4$ & $7 \pm 3$ & $-2 \pm 4$ & $-2 \pm 61$ & $8 \pm 5$ & $7 \pm 4$ & $-2 \pm 3$ & $-15 \pm 47 *$ \\
\hline Depression & $7 \pm 4$ & $6 \pm 4$ & $0 \pm 2$ & $18 \pm 64$ & $6 \pm 4$ & $7 \pm 4$ & $0 \pm 2$ & $2 \pm 34$ & $7 \pm 4$ & $5 \pm 4$ & $-2 \pm 3$ & $-|9 \pm 5| *$ \\
\hline Total & $16 \pm 7$ & $12 \pm 7$ & $-2 \pm 3$ & $-18 \pm 22 *$ & $14 \pm 6$ & $14 \pm 6$ & $-2 \pm 6$ & $-10 \pm 44$ & $15 \pm 7$ & $12 \pm 7$ & $-3 \pm 6$ & $-19 \pm 39 *$ \\
\hline
\end{tabular}

Notes: $* P<0.05$ between baseline and end of PRP; ${ }^{\ddagger} P<0.05$, significant difference between Nantes and Morlaix. Data presented as mean $\pm S D$.

Abbreviations: HADS, Hospital Anxiety and Depression Scale; 6MWD, 6-minute walk distance; PRP, pulmonary rehabilitation program; QMVC, quadriceps maximal voluntary contraction; SGRQ, St George's respiratory questionnaire.

\section{References}

1. Bolton CE, Bevan-Smith EF, Blakey JD, et al. British Thoracic Society guideline on pulmonary rehabilitation in adults. Thorax. 2013;68 Suppl 2: ii1-ii30.

2. Bernard S, Ribeiro F, Maltais F, Saey D. Prescribing exercise training in pulmonary rehabilitation: a clinical experience. Rev Port Pneumol. 2014;20(2):92-100.
3. Troosters T, Gosselink R, Decramer M. Six minute walking distance in healthy elderly subjects. Eur Respir J. 1999;14(2):270-274.
International Journal of COPD

\section{Publish your work in this journal}

The International Journal of COPD is an international, peer-reviewed journal of therapeutics and pharmacology focusing on concise rapid reporting of clinical studies and reviews in COPD. Special focus is given to the pathophysiological processes underlying the disease, intervention programs, patient focused education, and self management protocols

\section{Dovepress}

This journal is indexed on PubMed Central, MedLine and CAS. The manuscript management system is completely online and includes a very quick and fair peer-review system, which is all easy to use. Visit http://www.dovepress.com/testimonials.php to read real quotes from published authors. 